\title{
Meconium peritonitis resulting from different etiologies in siblings: a case report
}

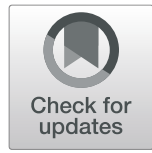

Kyung Hee Park', Mi Hye Bae ${ }^{1}$, Na Rae Lee ${ }^{2}$, Young Mi Han², Shin-Yun Byun ${ }^{2 *}$ (D) and Hae-Young Kim³

\begin{abstract}
Background: Meconium peritonitis is defined as aseptic chemical inflammation caused by intrauterine bowel perforation. The underlying causes of bowel perforation include intestinal atresia, midgut volvulus, intussusception, congenital bands, and meconium ileus.

Case presentation: Siblings with prenatally diagnosed meconium peritonitis of different etiologies were found. The elder sister was born at $36+6$ weeks gestation with a birth weight of $3110 \mathrm{~g}$. She was diagnosed with meconium peritonitis caused by ileal atresia. Two years later, the younger brother was born at $34+3$ weeks gestation with a birth weight of $2850 \mathrm{~g}$. He was diagnosed with meconium peritonitis caused by midgut volvulus.

Conclusions: Among the previously reported cases of meconium peritonitis, familial occurance of meconium peritonitis is extremely rare. We present a case of prenatally diagnosed meconium peritonitis in siblings to promote further understanding of its etiology and clinical course.
\end{abstract}

Keywords: Meconium peritonitis, lleostomy, Case report

\section{Background}

Meconium peritonitis (MP) is defined as aseptic chemical inflammation caused by an intrauterine bowel perforation. These perforations may result from mesenteric ischemia or obstruction, including intestinal atresia, volvulus, intussusceptions, meconium plug syndrome, inguinal hernia, Hischsprung's disease, and meconium ileus due to cystic fibrosis, in which the latest is rare in Asian populations [1,2]. Diagnostic features of MP are abdominal calcifications, ascites, polyhydramnios, meconium pseudocysts, echogenic masses, and a dilated bowel or intestinal obstruction. Recently, an increasing number of diagnoses via prenatal ultrasound have been reported. Clinical results and treatments are dependent on the individual features of MP.

\footnotetext{
* Correspondence: byun410@hanmail.net

This work was supported by a clinical research grant from Pusan National University Hospital 2019.

${ }^{2}$ Department of Pediatrics, Pusan National University Children's Hospital, Pusan National University School of Medicine, 20 Geumo-ro, Yangsan 50612, South Korea

Full list of author information is available at the end of the article
}

Among the previously reported cases of MP, familial occurance of MP is extremely rare. Only a few cases have been reported. We experienced siblings with prenatally diagnosed MP, caused by ileal atresia and midgut volvulus respectively.

\section{Case presentation}

Case 1

A $3110 \mathrm{~g}$ female baby was born at $36+6$ weeks gestation by cesarean section. Her mother was a 30 -year-old primigravid woman referred to our hospital at 28 weeks of gestation due to fetal ascites and polyhydroamnios, which were suspicious for MP. The patient was the first baby of healthy Korean parents. There was no family history of congenital anomalies. The patient had Apgar scores of 5 and 6 at 1 and 5 min, respectively. The body length was $45 \mathrm{~cm}(10-25$ percentile) and head circumference was $34 \mathrm{~cm}$ (75-90 percentile).

After birth, the baby had respiratory difficulties. She was intubated and mechanically ventilated. She showed mild abdominal distension. A plain abdominal X-ray showed 


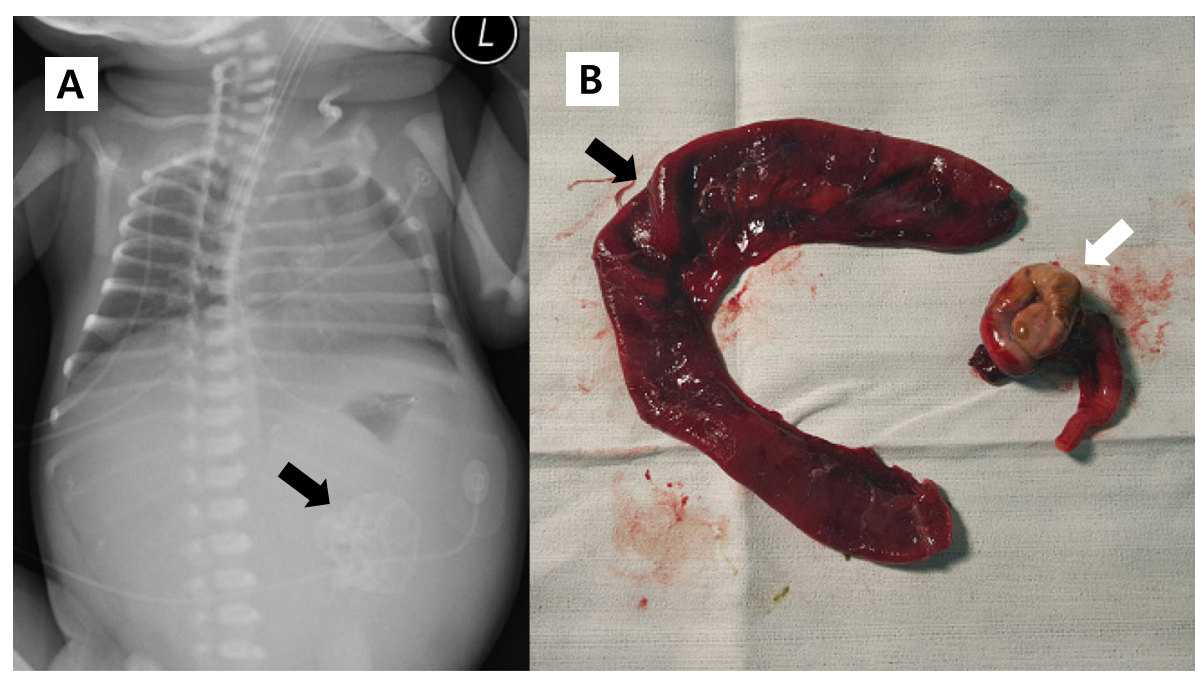

Fig. 1 a A plain abdominal X-ray showing a calcified mass-like density in the left mid-abdomen (arrow). b A markedly distended proximal pouch in the ileum (arrow) and calcified distal pouch (white arrow), was resected

bulging flanks, an elevated diaphragm, and a calcified mass-like density in the left mid-abdomen (Fig. 1a). A laparotomy on the second day of life revealed a large amount of greenish peritoneal fluid with free meconium. A markedly dilated proximal segment ending blindly was found in the ileum $100 \mathrm{~cm}$ distal to the Treitz ligament and a perforation was found in the distal pouch corresponding to the calcification in the abdominal X-ray (Fig. 1b). We diagnosed her ileal atresia with perforation in the distal pouch. Affected proximal and distal pouches were resected, and a primary anastomosis was performed.

Her respiratory symptoms improved after operation. She was extubated 1 day post-operatively. Feeding was started on post-operative day 7 and she showed gradual improvement. The remainder of her hospital course was uneventful, and she was discharged at 18 days of life. The patient's karyotype was normal (46, XX). Laboratory studies were all normal. At her 3-year follow-up, patient condition was good with normal weight gain and development milestones.

\section{Case 2}

The parents had a second pregnancy 2 years later. No fetal abnormalities were detected until 24 weeks of gestation at serial fetal ultrasounds, which revealed a mildly dilated and echogenic bowel and ascites. Serial fetal ultrasound showed increasing ascites. At $34+3$ weeks gestation, an emergency cesarean section was performed due to fetal distress with prolonged deceleration on a non-stress test.

The male baby, weighing $2850 \mathrm{~g}$, was delivered with Apgar scores of 4 and 7 at 1 and $5 \mathrm{~min}$, respectively. The baby showed signs of respiratory distress and a markedly distended abdomen. He was intubated and required assisted ventilation. A chest radiograph showed diffuse haziness on both lung fields and a bilaterally elevated diaphragm. An abdominal X-ray showed bulging flanks and a gasless abdomen, but no calcification (Fig. 2a). He was diagnosed with respiratory distress syndrome and surfactant was administrated. Despite surfactant administration, his lungs worsened. Therefore, an emergency laparotomy was performed $3 \mathrm{~h}$ after birth. Intraoperative findings showed a $20 \mathrm{~cm}$-sized volvulus in the distal jejunum with meconium-stained ascites occupying the abdomen (approximately $300 \mathrm{ml}$ ). A perforation was found in jejunum proximal to volvulus and the affected jejunum was markedly dilated (Fig. 2b). We resected dilated proximal jejunum and distal necrotic intestine of the volvulus and performed a primary anastomosis.

After the operation, his respiratory symptoms improved. However, not long after laparotomy, his lung deteriorated and gradually developed bronchopulmonary dysplasia. Unfortunately, his bowel function did not improve until 2 weeks of life. Therefore, at 15 days of life, an exploratory laparotomy was performed. Severe adhesion was found at around the primary anastomosis site. After peritoneal adhesiolysis, ileostomy $10 \mathrm{~cm}$ dital to primary anastomosis site was performed. After the ileostomy, the baby began feeding and tolerated it well. Four weeks later, an ileostomy closure was performed.

He regained bowel function on post-operative day 8 and initiated low volume enteral feeds with gradual advancement. We attempted to wean the patient off mechanical ventilation several times but failed. After steroid administration, he was extubated successfully at 2 months of age but he suffered from oxygen dependency and cholestasisassociated parenteral nutrition during the remainder of 


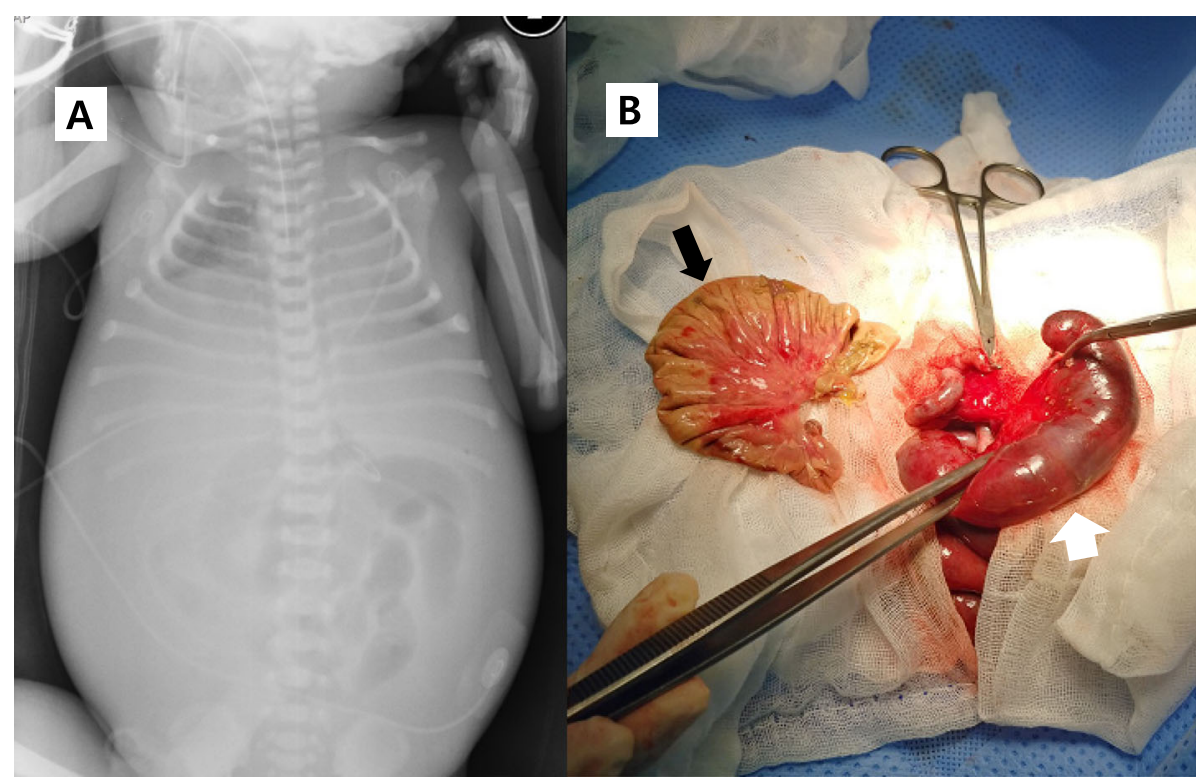

Fig. 2 a A chest radiograph showing diffuse haziness on both lung fields and a bilaterally elevated diaphragm. b The dilated small bowel proximal to volvulus (arrow) was resected and volvus (white arrow) was seen necrotic

his hospitalization. He was discharged at 4 months of age. The patient's karyotype was normal (46, XY). Laboratory studies, were all normal.

\section{Discussion and conclusions}

Among the previously reported cases of MP, MP in siblings is very rare $[3,4]$. So far, only two cases have been reported. First, Shyu et al. reported a patient with MP in Taiwan [3]. That patient had a deceased brother whose autopsy revealed meconium peritonitis and hydrocephalus but no intestinal perforation or malformation. In that patient, intrauterine paracentesis was done and the exact cause of MP remained unknown. We couldn't know whether that was a case of true familial occurance of MP because one of the siblings was stillborn and neither had any intestinal perforations detected.

Second, Chitayat et al. reported on siblings (a brother and a sister) who presented prenatally with ultrasound findings of MP and were postnatally found to have a perforation of the terminal ileum [4]. However, our patients presented slightly differently from those two previous familial cases. While both of our patients were prenatally diagnosed with MP, the causes of intestinal perforation were different in each sibling (ileal atresia for one sibling, and midgut volvulus for the other).

The pathogenesis of MP is not well understood [4]. Most cases have been idiopathic and sporadic although some cases have been attributed to chromosome abnormalities or cystic fibrosis. Especially, a cystic fibrosis is a known underlying cause of MP in western countries, but is extremely rare in Asian countries [4]. Not only cystic fibrosis is rare in Korean population, but our patients showed intestinal atresia and volvulus rather than meconium ileus [5]. So we could rule out cystic fibrosis.

A decrease in blood flow to the mesentery may lead to mucosal necrosis and subsequent bowel obstruction and perforation of the intestinal wall [6]. According to this theory, it is likely that our patients' mother was repeatedly exposed to an ischemic environment. However, there was no medical or social history of maternal smoking or vasoconstrictor drug exposure during pregnancy. There is no clear explanation as to why ischemic insults repeatedly occur only in the small intestines of these siblings.

On the other hand, a genetic origin, especially autosomal recessive inheritance, is postulated due to patient reports of affected siblings (different sex) born to unaffected parents. The current case is in accordance with a previous report by Chitayat et al. reporting siblings with MP [4]. However, unfortunately both their patients and our siblings were not performed the genetic test such as whole exome sequencing. In addition, coincidence cannot be ruled out. MP has been reported to have an incidence of one in 30,000-35,000 live births [7-9]. Therefore, the possibility of coincidence like our case must be one in $10^{9}$.

We do not know whether MP of our case was due to genetic abnormality or coincidence. More studies and case reports including genetic evaluations are required to determine the exact cause of familial occurance of MP including siblings. We present a case of MP in siblings to promote further understanding of the etiology and clinical course. Our case is the first report of MP in siblings resulting from different causes (ileal atresia and 
midgut volvulus). We need to know that MP was occurred in the siblings, so that we can predict and respond the similar situation in following pregnancy with previous meconium peritonitis history.

\section{Abbreviation}

MP: Meconium peritonitis

\section{Acknowledgments}

We thank the parents of our patient for their cooperation and for providing consent for publication.

\section{Authors' contributions}

$\mathrm{MH}, \mathrm{NR}, \mathrm{YM}, \mathrm{SY}, \mathrm{HY}$ and $\mathrm{KH}$ were involved in the clinical management of these patients, collected clinical details and photographs of this case report. The author(s) read and approved the final manuscript.

\section{Funding}

This work was supported by a clinical research grant from Pusan National University Hospital 2019 to Dr. Kyung Hee Park. This fund was contributed in the process of information collection, analysis, and interpretation of data in writing of this manuscript.

\section{Availability of data and materials}

All data generated or analyzed during this study are included in this published article.

\section{Ethics approval and consent to participate}

All of this study complied with the requirement of "The Ethics of Clinical Research" issued by Ministry of Health and Welfare, Korea. All procedures performed were in accordance with the ethical standards of "Pusan National University School of Medicine Research Committee".

\section{Consent for publication}

A written informed consent was obtained from the parents of patients for publication of this case report.

\section{Competing interests}

The authors declare that they have no competing interests.

\section{Author details}

'Department of Pediatrics, Pusan National University Hospital, Pusan National University School of Medicine, Busan, South Korea. ${ }^{2}$ Department of Pediatrics, Pusan National University Children's Hospital, Pusan National University School of Medicine, 20 Geumo-ro, Yangsan 50612, South Korea. ${ }^{3}$ Department of Surgery, Pusan National University Hospital, Busan, South Korea.

Received: 14 January 2020 Accepted: 28 February 2020

Published online: 05 March 2020

\section{References}

1. Reynolds E, Douglass B, Bleacher J. Meconium peritonitis. J Perinatol. 2000; 20:193-5.

2. Chang PY, Huang FY, Yeh ML, Sheu JC, Chen BF, Chen CC. Meconium ileuslike condition in Chinese neonates. J Pediatr Surg. 1992;27:1217-9. https:// doi.org/10.1016/0022-3468(92)90791-5.

3. Shyu MK, Chen CD, Hsieh FJ, Yau KI, Lin GJ, Lee ML. Intrauterine intervention in a case of recurrent meconium peritonitis. Prenat Diagn. 1994;14:9935. https://doi.org/10.1002/pd.1970141016.

4. Chitayat D, Grisaru-Granovsky S, Ryan G, Toi A, Filler R, Seaward GR, SiegelBartelt J, Cytrynbaum C. Familial ileal perforation: prenatal diagnosis and postnatal follow-up. Prenat Diagn. 1998;16:78-82.

5. Ko JM, Kim GH, Kim KM, Hong SJ, Yoo HW. Identification of a novel mutation of CFTR gene in a Korean patient with cystic fibrosis. J Korean Med Sci. 2008:23(5):912-5.

6. Tibboel D, Gaillard JL, Molenaar JC. The importance of mesenteric vascular insufficiency in meconium peritonitis. Hum Pathol. 1986;17:411-6. https:// doi.org/10.1016/s0046-8177(86)80466-X.

7. Foster MA, Nyberg DA, Mahony BS, Mack LA, Marks WM, Raabe RD. Meconium peritonitis: prenatal sonographic findings and their clinical significance. Radiology. 1987;165:661-5. https://doi.org/10.1148/radiology. 165.3.3317498.

8. Ohmichi M, Kanai H, Kanzaki T, Matumoto K, Neki R, Chiba Y, Kamata S, Murata Y. Meconium peritonitis; changes in fetal C-reactive protein and CA 125 levels in relation to stage of disease. J Ultrasound Med. 1997;16:289-92. https://doi.org/10.7863/jum.1997.16.4.289.

9. Wang Y, Wu Y, Guan W, Yan W, Li Y, Fang J, et al. Meconium peritonitis due to fetal appendiceal perforation: two case reports and a brief review of the literature. BMC Pediatr. 2018:18(1):162.

\section{Publisher's Note}

Springer Nature remains neutral with regard to jurisdictional claims in published maps and institutional affiliations.

\section{Ready to submit your research? Choose BMC and benefit from:}

- fast, convenient online submission

- thorough peer review by experienced researchers in your field

- rapid publication on acceptance

- support for research data, including large and complex data types

- gold Open Access which fosters wider collaboration and increased citations

- maximum visibility for your research: over $100 \mathrm{M}$ website views per year

At $\mathrm{BMC}$, research is always in progress.

Learn more biomedcentral.com/submissions 